Full length article

\title{
Inhibitory effect of IQ-1S, a selective c-Jun N-terminal kinase (JNK) inhibitor, on phenotypical and cytokine-producing characteristics in human macrophages and T-cells
}

\author{
Victor I. Seledtsov ${ }^{\mathrm{a}, \mathrm{b}, *}$, Vladimir V. Malashchenko ${ }^{\mathrm{a}}$, Maksim E. Meniailo ${ }^{\mathrm{a}}$, Dmitriy N. Atochin ${ }^{\mathrm{c}, \mathrm{d}}$, \\ Galina V. Seledtsova ${ }^{e}$, Igor A. Schepetkin ${ }^{c, f}$ \\ ${ }^{a}$ Center for Medical Biotechnologies, Immanuel Kant Baltic Federal University, Kaliningrad, 236016, Russia \\ ${ }^{\mathrm{b}}$ Innovita Research Company, Vilnius, LT-06118, Lithuania \\ ${ }^{\mathrm{c}}$ Kizhner Research Center, Tomsk Polytechnic University, Tomsk, 634050, Russia \\ ${ }^{\mathrm{d}}$ Cardiovascular Research Center, Cardiology Division, Massachusetts General Hospital, Harvard Medical School, Charlestown, MA, 02129, USA \\ ${ }^{\mathrm{e}}$ Laboratory for Cellular Technologies, Scientific Research Institute for Fundamental and Clinical Immunology, Novosibirsk, 630099, Russia \\ ${ }^{\mathrm{f}}$ Department of Microbiology and Immunology, Montana State University, Bozeman, MT, 59717, USA
}

\section{A R T I C L E I N F O}

\section{Keywords:}

c-Jun N-Terminal kinase

JNK inhibitor

Monocyte/macrophage

T cell

CD expression

Cytokine

Anti-inflammatory

\begin{abstract}
A B S T R A C T
c-Jun N-terminal kinase (JNK) is a critical mitogen activated protein kinase (MAPK) implicated in inflammatory processes, with IQ-1S (11H-indeno[1,2-b]quinoxalin-11-one oxime sodium salt) being a high-affinity JNK inhibitor with pronounced anti-inflammatory properties. Here, we studied direct effects of IQ-1S on phenotypical and cytokine-producing characteristics of activated human monocytes/macrophages and T cells in vitro. Purified monocyte/macrophage cells were activated by bacterial lipopolysaccharide (LPS, $1 \mu \mathrm{g} / \mathrm{ml}$ ) for $24 \mathrm{~h}$, while T cells were activated by particles conjugated with antibodies (Abs) against human CD2, CD3, and CD28 for $48 \mathrm{~h}$. Treatment with IQ-1S (0.5-25 $\mu \mathrm{M})$ in the presence of LPS reduced percentages of CD197 (CCR7)-positive cells in macrophage cultures, without affecting CD16 ${ }^{+}$(Fc $\gamma$ RIII, low-affinity Fc-receptor), CD119 ${ }^{+}$(interferon- $\gamma$ receptor 1), and CD124+ (IL-4 receptor $\alpha$-subunit) cells. In addition, IQ-1S reduced production of tumour necrosis factor- $\alpha$ (TNF- $\alpha$ ), interleukin-1 $\beta$ (IL-1 $\beta$ ), IL-6, and IL-10 in macrophage cultures. In activated T cell cultures, IQ$1 \mathrm{~S}$ decreased CD25 ${ }^{+}$cell numbers in both CD4-positive and CD4-negative T cell compartments. Central memory $\mathrm{CD} 4 \mathrm{RA}^{-} / \mathrm{CD} 197^{+}$and effector memory CD45RA ${ }^{-} / \mathrm{CD}^{-} 197^{-} \mathrm{T}$ cells were more sensitive to IQ-1S-mediated suppression, as compared to naïve $\mathrm{CD}_{4} 5 \mathrm{RA}^{+} / \mathrm{CD} 197^{+}$and terminally-differentiated effector $\mathrm{CD} \mathrm{CRA}^{+} / \mathrm{CD} 197^{-}$ T cells. IQ-1S also suppressed T-cell cytokine production (IL-2, interferon-y, IL-4, and IL-10). Collectively, the results suggest that both human macrophage and $\mathrm{T}$ cells could be immediate cell targets for IQ-1S-based antiinflammatory immunotherapy. IQ-1S-mediated suppressive effects were unlikely to be associated with macrophage/T helper polariation.
\end{abstract}

\section{Introduction}

Activating protein 1 (AP-1) and nuclear factor- $\mathrm{B}$ (NF- $\mathrm{BB}$ ) transcription factors play pivotal roles in controlling expression of pro-inflammatory mediators involved in many physiological and pathological processes, such as lymphoid differentiation, inflammation, apoptosis and immune responses (Peng, 2008; Shvedova et al., 2018). Although AP-1 and NF- $\mathrm{KB}$ are regulated by different signaling pathways, NF- $\mathrm{\kappa B} /$ AP-1 cross-talk is known to ensue via such mechanisms as: (i) interactions between c-Jun and c-Fos major AP-1 family proteins with the p65

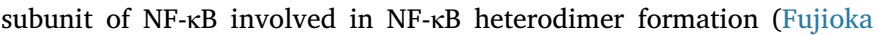

et al., 2004), and (ii) activation of the NF-кB inhibitor (ІкB) kinase complexes at the transcriptional level achieved primarily via extracellular signal-regulated protein kinases (ERK), p38, and c-Jun Nterminal kinase (JNK) (Bhagwat, 2009). Three genes encoding JNK1, JNK2, and JNK3 and at least 10 different splice variants have been described in mammalian cells (Gupta et al., 2010). JNK1 and JNK2 are expressed ubiquitously in many tissues, whereas JNK3 expression is limited to the brain, heart and testis (Bogoyevitch et al., 2010).

Down-regulation of NF- $\mathrm{BB} / \mathrm{AP}-1$ signaling pathways by various pharmacological compounds and small-molecules is a well-established drug discovery area. In particular, the direct involvement of JNKs in

\footnotetext{
* Corresponding author. Innovita Research Company, Vilnius, LT-06118, Lithuania.

E-mail address: seledtsov@rambler.ru (V.I. Seledtsov).
} 
AP-1 transcriptional activity regulation substantiated extensive drug discovery efforts aiming to develop novel JNK inhibitors for curing chronic inflammatory diseases (Wagner and Laufer, 2006; Gupta et al., 2010; Jung et al., 2010). Indeed, there is a large body of evidence supporting the idea that JNK inhibitors could have high potential as anti-inflammatory, antiapoptotic, neuroprotective, and cardioprotective drugs with a very promising therapeutics development perspective (Bennett et al., 2003Bogoyevitch et al., 2010; Schepetkin et al., 2012, 2015; Shvedova et al., 2018).

A high-affinity small molecule JNK inhibitor IQ-1S (11H-indeno [1,2-b]quinoxalin-11-one oxime sodium salt) has been developed to display high potency and a few number of kinase off-targets (Schepetkin et al., 2012). In addition, IQ-1S was found to be a potent non-cytotoxic inhibitor of pro-inflammatory cytokine production in activated immune cells demonstrating also a strong anti-inflammatory potential in a murine delayed-type hypersensitivity model (Schepetkin et al., 2012). In experimental settings, IQ-1S inhibited matrix metalloproteinase 1 and 3 gene expression in interleukin (IL)-1 $\beta$-induced human fibroblast-like synoviocytes (in vitro); in addition, IQ-1S treatment significantly attenuated murine collagen-induced arthritis (CIA) paralleled by reductions in collagen II-specific antibody responses (Schepetkin et al., 2015).

We hypothesised that major immunological and tissue-protective effects of IQ-1S could be explained by its effects on adaptive immunogenesis. Therefore, in this study we addressed direct effects of IQ1S on phenotypical and cytokine-producing characteristics of human monocytes/macrophages and $\mathrm{T}$ cells, which are pivotal players in adaptive immune responses. We report profound IQ-1S-mediated inhibition with respect to both macrophages and $\mathrm{T}$ cells, which sheds further light on the mechanisms underlying immunosuppressive effects of this promising immunotherapeutic drug candidate.

\section{Materials and methods}

Study protocol was approved by the Committee on Human Research, Immanuel Kant Baltic Federal University (№7/March 10, 2015).

\subsection{JNK inhibitor}

IQ-1S was synthesized as previously described (Pearson, 1962). IQ$1 \mathrm{~S}$ was dissolved in dimethyl sulfoxide (DMSO) and added to the cell cultures at final concentrations of $0.5,5$, and $25 \mu \mathrm{M}$. Matching concentrations of DMSO were used as negative controls. No significant biological effects of DMSO were observed in our experimental models.

\subsection{Isolation of cells}

Heparinized blood samples were taken from median cubital vein of 14 healthy donors (both men and women aged 21-40 years) according to a standard clinical procedure. Signed informed consent forms were obtained from all donors. Peripheral blood mononuclear cells (PBMCs) were isolated from blood using Ficoll-Paque (Ficoll-Paque ${ }^{\mathrm{TM}}$ PREMIUM, $1.077 \mathrm{~g} / \mathrm{ml}$, GE Healthcare, USA) gradient centrifugation. CD14-positive cells were isolated from PBMCs by magnetic column separation (MS columns, Miltenyi Biotec, Bergisch Gladbach, Germany) using CD14 MicroBeads (CD14 Micro Beads human, Miltenyi Biotec). $\mathrm{CD}^{+} \mathrm{T}$ lymphocytes were also isolated by magnetic column separation using CD3 MicroBeads (CD3 Micro Beads human, Miltenyi Biotec). All procedures were performed exactly as specified in the manufacturer's instruction. Cells were counted using a Z2 Cell and Particle counter (Beckman Coulter Inc., Fullerton, USA).

\subsection{Cell cultures}

Isolated CD14-positive cells were cultured at $1.0-1.5 \times 10^{6} / \mathrm{ml}$ in 24-well plates in the presence or absence of bacterial LPS $(1 \mu \mathrm{g} / \mathrm{ml}$, Salmonella typhi, Pyrogenalum, Medgamal, Scientific Research Institute of Epidemiology and Microbiology named after N. F. Gamalei, Russia) in a serum-free cell culture medium TexMACS ${ }^{\mathrm{TM}}$ (Miltenyi Biotec) supplemented with $50 \mu \mathrm{M}$ of 2-mercaptoethanol (Acros Organics/Thermo Fisher Scientific, NJ, USA) in a humidified $\mathrm{CO}_{2}$ incubator at $37{ }^{\circ} \mathrm{C}$ for $24 \mathrm{~h}$. Isolated T cells were cultured at $1.0-1.5 \times 10^{6} / \mathrm{ml}$ in the presence or absence of MACSiBead particles conjugated with antibodies (Abs) against human CD2, CD3, and CD28 (human T Cell Activation/ Expansion Kit, MACS Miltenyi Biotec) in the same cell culture medium for $48 \mathrm{~h}$. Both monocytes/macrophages and T cells were cultured in the absence (negative controls with DMSO) or presence (test cultures) of IQ-1S dilutions specified above.

\subsection{Flow cytometry and assessment of cell viability}

Surface characteristics of macrophage cells were studied by staining with a cocktail of the following specific monoclonal antibody (Ab)based reagents: peridinin chlorophyll (PerCP)-labelled anti-CD14 (eBioscience, USA), fluorescein isothiocyanate (FITC)-labelled antiCD16, phycoerythrin (PE)-labelled anti-CD119, allophycocyanin (APC)labelled anti-CD124, and PE/Alexa Fluor ${ }^{\circledR}$ 488-labelled anti-CD197 (BioLegend, San Diego, CA, USA). Phenotype of various T cell subsets was analysed using the following Ab reagents: CD4-PerCP, CD115-FITC (eBioscience, San Diego, CA, USA), CD197-PE, CD45RA-APC (BD Pharmingen, San Jose, CA, USA), and CD25-FITC (BioLegend). Cell viability was assessed by staining with a membrane impermeable dye propidium iodide (eBioscience) followed by flow cytometry. Single stained samples were used to determine the levels of compensation for spectral overlaps. Positive/negative boundaries and non-specific binding were established by using unstained controls and fluorescence minus one controls. To account for the nonspecific antibody binding, we used isotype controls (Iso IgG2a for APC, PE, AF488; Iso IgG1 for FITC, PE) (BioLegend). Flow cytometry was performed on a BD Accuri ${ }^{\text {TM }}$ C6 flow cytometer (BD Biosciences, San Jose, CA, USA), and data analysis was done using BD Accuri ${ }^{\mathrm{TM}}$ C6 Software package (BD Biosciences).

\subsection{ELISA}

Concentrations of IL-1 $\beta$, IL-2, IL-4, IL-10, IL-6, interferon- $\gamma$ (IFN- $\gamma$ ), and tumor necrosis factor (TNF) in cell culture supernatants were measured using commercially available ELISA kits (Vector-Best, Novosibirsk, Russia), according to the manufacturer's instructions, using an Automated EIA and Chemistry Analyzer (ChemWell 2910, Awareness Technology, Inc., Palm City, FL, USA).

\subsection{Statistical analysis}

Statistical analysis was performed using IBM SPSS Statistics for Windows, version 20.0 (IBM Corp., Armonk, NY, USA). None of the quantitative variables in the comparison groups were normally distributed according to the Kolmogorov-Smirnov test. Therefore, comparison between independent groups was performed using the MannWhitney U test. Median (Me) with the first and third quartiles [Me (Q1Q3)] were calculated for the variables in the comparison groups. $\mathrm{P}<0.05$ was considered statistically significant.

\section{Results}

3.1. IQ-1S-mediated effects on phenotype and cytokine production patterns of monocytes/macrophages

In our previous reports, we established a multi-color flow cytometry protocol and appropriate gating strategy that enabled us to identify CD14 (LPS co-receptor) ${ }^{+}$, CD16 (Fc $\gamma$ RIII, low-affinity Fc-receptor) ${ }^{+}$, 
a

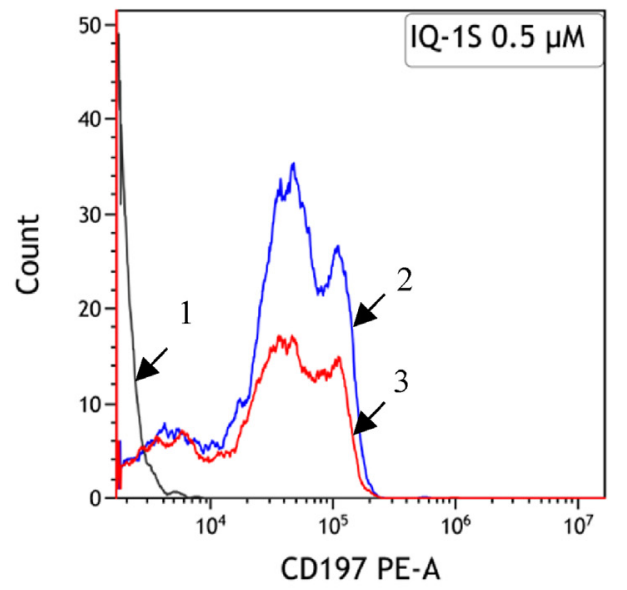

b

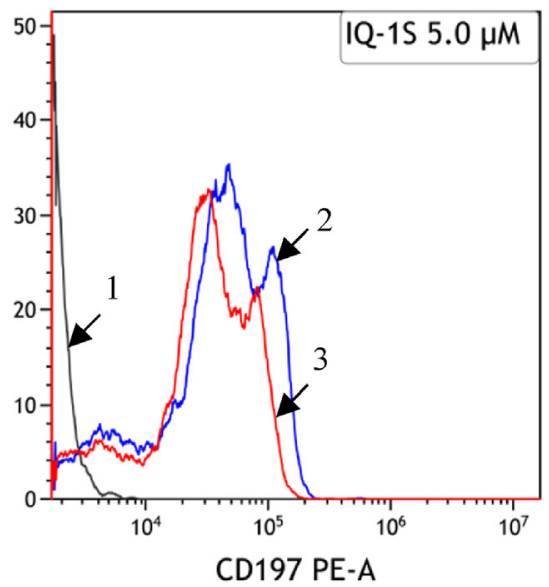

c

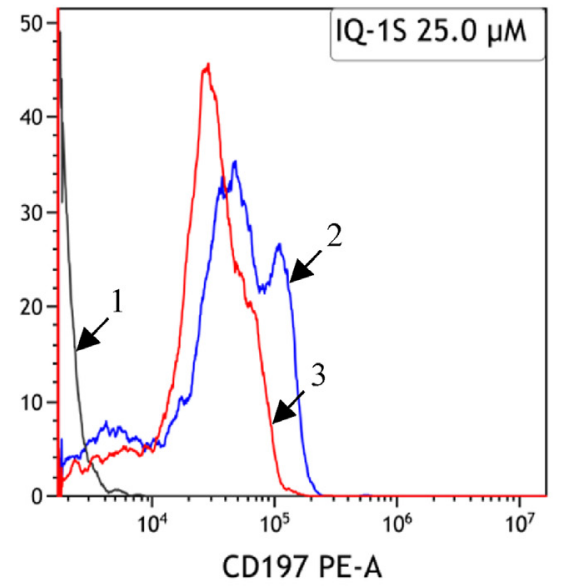

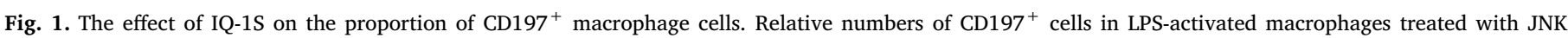

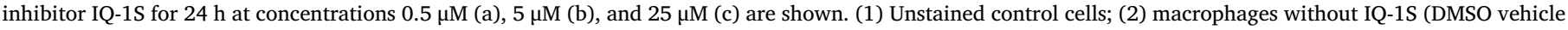
control); (3) macrophages with IQ-1S.

CD119 (IFN- $\gamma$ receptor 1$)^{+}$, CD124 (IL-4 receptor $\alpha$-subunit) ${ }^{+}$, and CD197 (CCR7) ${ }^{+}$monocyte/macrophage cells (; Meniailo et al., 2018Melashchenko et al., 2018). In this study, purity of CD14-positive cells isolated from blood by positive magnetic separation was $98.7 \%$ (92.5-99.4), with cell viability of 96.3\% (94.0-99.8) (Meniailo et al., 2018).

IQ-1S-mediated effects on the expression of membrane markers related to the functional macrophage activity remain largely unknown. In our experiments, treatment of monocytes/macrophages with IQ-1S for $24 \mathrm{~h}$ in the absence of LPS did not affect significantly relative numbers of $\mathrm{CD} 16^{+}, \mathrm{CD} 119^{+}, \mathrm{CD} 124^{+}, \mathrm{CD}_{197^{+}}$cells (data not shown). Activation of monocyte/macrophage cultures with LPS significantly augmented relative numbers of $\mathrm{CD}_{197}{ }^{+}$cells (from $8 \%$ to $20 \%$ ) without affecting other macrophage subsets tested (Meniailo et al., 2018). As can be seen in Fig. 1 and Table 1, IQ-1S significantly reduced percentages of $\mathrm{CD}_{197}{ }^{+}$cells in LPS-activated macrophage cultures. Importantly, a pronounced dose-dependent suppressive effect was registered across the entire IQ-1S concentration range including the lowest dose of $0.5 \mu \mathrm{M}$, which was much lower than the $20 \mu \mathrm{M}$ dose used in previously reported experiments in vitro (Schepetkin et al., 2012). IQ1S had no effects on other macrophage subpopulations tested.

Treatment of LPS-activated human PBMCs with IQ-1S at $20 \mu \mathrm{M}$ has been shown previously to reduce drastically production of TNF, IL-1 $\beta$, IL-6, and IL-10 (Schepetkin et al., 2012). We found that IQ-1S did not significantly affect cytokine production patterns in healthy donor

Table 1

Effects of JNK inhibitor IQ-1S on expression of membrane markers in LPS-activated macrophages.

\begin{tabular}{lllll}
\hline \multirow{2}{*}{ Marker } & \multicolumn{4}{l}{ IQ-1S concentration $(\mu \mathrm{M})$} \\
\cline { 2 - 5 } & 0 & 0.5 & 5 & 25 \\
\hline \multirow{2}{*}{ CD16 } & 19 & 19 & 19 & 13 \\
& $(17-50)$ & $(9-45)$ & $(8-35)$ & $(6-28)$ \\
CD119 & 89 & 89 & 94 & 93 \\
& $(50-97)$ & $(74-98)$ & $(84-99)$ & $(85-99)$ \\
CD124 & 50 & 47 & 48 & 52 \\
& $(30-63)$ & $(35-50)$ & $(22-52)$ & $(14-54)$ \\
CD197 & 20 & 7 & 5.6 & 2 \\
& $(9-22)$ & $(6-8)^{*}$ & $(3-7)^{*}$ & $(1-6)^{*}$ \\
\hline
\end{tabular}

Macrophage cells were activated by LPS $(1 \mu \mathrm{g} / \mathrm{ml})$ for $24 \mathrm{~h}$ in the presence of the indicated concentrations of IQ-1S. The results of 5 experiments are presented. Percentages of macrophages expressing appropriate markers are shown. ${ }^{*} \mathrm{P}<0.05$, as compared to macrophage in the absence of IQ-1S.
Table 2

The effects of IQ-1S on cytokine production by LPS-activated macrophage cells.

\begin{tabular}{lllll}
\hline Cytokine & \multicolumn{2}{l}{ IQ-1S concentration $(\mu \mathrm{M})$} & \\
\cline { 2 - 5 } & 0 & 0.5 & 5 & 25 \\
\hline TNF & 1870 & 1631 & $286^{*}$ & $239^{*}$ \\
& $(1313-2436)$ & $(917-1939)$ & $\begin{array}{l}(6-969) \\
12^{*}\end{array}$ & $\begin{array}{l}(10-1056) \\
<10 *\end{array}$ \\
IL-1 $\beta$ & 516 & 646 & $(5-151)$ & \\
& $(448-988)$ & $(402-891)$ & $386^{*}$ & $90^{*}$ \\
IL-6 & 17004 & $12834^{*}$ & $(327-3142)$ & $(5-514)$ \\
& $(13217-17501)$ & $(10394-14310)$ & $<10^{*}$ & $<10^{*}$ \\
IL-10 & 158 & $99^{*}$ & & \\
& $(135-265)$ & $(89-147)$ & &
\end{tabular}

Macrophage cells were activated by LPS $(1 \mu \mathrm{g} / \mathrm{ml})$ for $24 \mathrm{~h}$ in the presence of the indicated concentrations of IQ-1S. The results of 5 experiments are presented. Cytokine concentrations in cell supernatants $(\mathrm{pg} / \mathrm{ml})$ are shown. ${ }^{*} \mathrm{P}<0.05$, as compared to macrophage cells in the absence of IQ-1S.

blood-derived monocyte/macrophage cell cultures in the absence of LPS activation stimuli (data not shown). However, IQ-1S was effective in inhibiting production of all cytokines studied in LPS-activated macrophages (Table 2). Interestingly, IL-6 and IL-10 production was more sensitive to the IQ-1S-mediated suppressive effect, as compared to TNF and IL- $1 \beta$ production.

\subsection{Effects of IQ-1S on phenotype and cytokine production patterns of $T$ cells}

JNK are important players in T-cell activation, differentiation, and cytokine production (Rincón and Pedraza-Alva, 2003; Rincón and Davis, 2009). Treatment of mice with IQ-1S has been shown to increase the number of Foxp $3^{+} \mathrm{CD} 4^{+} \mathrm{CD} 25^{+}$regulatory $\mathrm{T}$ cells in lymph nodes (Schepetkin et al., 2012), but direct effects of IQ-1S on various T cell subpopulations are poorly understood. Therefore, this part of the study was designed to address this important issue. We applied a multi-colour flow cytometry protocol to identify human CD4-positive and CD4-negative T cells, with their further subclassification into naïve CD45RA ${ }^{+}$, $\mathrm{CD}_{197^{+}}$, central memory $\mathrm{CD}_{4} \mathrm{RA}{ }^{-} / \mathrm{CD} 197^{+}$, effector memory CD45RA $^{-} / \mathrm{CD}_{197}$, and terminally-differentiated effector CD45RA ${ }^{+}$/ CD197 $\mathrm{T}$ cells, as described in detail in our previous reports (Shmarov et al., 2016; Todosenko et al., 2016; Meniailo et al., 2017; Malashchenko et al., 2018). In these experiments, purity of $\mathrm{T}$ cells isolated from PBMCs by magnetic separation was 98.6\% (94.7-99.2), with the baseline viability of $95.4 \%$ (94.1-99.4) (Shmarov et al., 2016; 
Table 3

The effects of IQ-1S on relative numbers of $\mathrm{CD}_{2} 5^{+} \mathrm{T}$ cells in various $\mathrm{T}$ cell subpopulations.

\begin{tabular}{|c|c|c|c|c|c|}
\hline & \multirow[t]{2}{*}{$\mathrm{T}$ cell subpopulation } & \multicolumn{4}{|c|}{ IQ-1S concentrations $(\mu \mathrm{M})$} \\
\hline & & 0 & 0.5 & 5 & 25 \\
\hline \multirow[t]{4}{*}{$\mathrm{CD} 4^{+}$} & $\mathrm{CD} 45 \mathrm{RA}^{+} / \mathrm{CD} 197^{+}$ & $\begin{array}{l}3 \\
(2-4)\end{array}$ & $\begin{array}{l}2 \\
(1-4)\end{array}$ & $\begin{array}{l}2 \\
(1-4)\end{array}$ & $\begin{array}{l}1^{*} \\
(0.1-3.4)\end{array}$ \\
\hline & $\mathrm{CD} 45 \mathrm{RA}^{-} / \mathrm{CD} 197^{+}$ & $\begin{array}{l}8 \\
(5-11)\end{array}$ & $\begin{array}{l}8 \\
(4-18)\end{array}$ & $\begin{array}{l}6 \\
(3-9)\end{array}$ & $\begin{array}{l}3^{*} \\
(1-5)\end{array}$ \\
\hline & $\mathrm{CD} 4 \mathrm{RA}^{-} / \mathrm{CD}^{-197^{-}}$ & $\begin{array}{l}21 \\
(13-33)\end{array}$ & $\begin{array}{l}11 \\
(5-25)\end{array}$ & $\begin{array}{l}8^{*} \\
(2-25)\end{array}$ & $\begin{array}{l}12^{*} \\
(1-17)\end{array}$ \\
\hline & $\mathrm{CD} 4 \mathrm{RA}^{+} / \mathrm{CD} 197^{-}$ & $\begin{array}{l}28 \\
(3-43)\end{array}$ & $\begin{array}{l}18 \\
(2-32)\end{array}$ & $\begin{array}{l}12 \\
(3-24)\end{array}$ & $\begin{array}{l}12^{*} \\
(1-29)\end{array}$ \\
\hline \multirow[t]{4}{*}{$\mathrm{CD}^{-}$} & $\mathrm{CD} 45 \mathrm{RA}^{+} / \mathrm{CD} 197^{+}$ & $\begin{array}{l}4 \\
(1-9)\end{array}$ & $\begin{array}{l}3 \\
(1-7)\end{array}$ & $\begin{array}{l}1 \\
(0.7-6.1)\end{array}$ & $\begin{array}{l}1^{*} \\
(0.1-2.3)\end{array}$ \\
\hline & $\mathrm{CD} 45 \mathrm{RA}^{-} / \mathrm{CD} 197^{+}$ & $\begin{array}{l}20 \\
(6-28)\end{array}$ & $\begin{array}{l}4.8 \\
(2-27)\end{array}$ & $\begin{array}{l}3^{*} \\
(2-15)\end{array}$ & $\begin{array}{l}3^{*} \\
(1-5)\end{array}$ \\
\hline & $\mathrm{CD}^{2} 5 \mathrm{RA}^{-} / \mathrm{CD}^{-197}$ & $\begin{array}{l}21 \\
(12-33)\end{array}$ & $\begin{array}{l}11 \\
(5-25)\end{array}$ & $\begin{array}{l}8^{*} \\
(2-25)\end{array}$ & $\begin{array}{l}2 * \\
(1-6)\end{array}$ \\
\hline & $\mathrm{CD} 45 \mathrm{RA}^{+} / \mathrm{CD} 197^{-}$ & $\begin{array}{l}23 \\
(15-33)\end{array}$ & $\begin{array}{l}17 \\
(10-36)\end{array}$ & $\begin{array}{l}10^{*} \\
(3-25)\end{array}$ & $\begin{array}{l}1.3^{*} \\
(0.1-11.1)\end{array}$ \\
\hline
\end{tabular}

$\mathrm{T}$ cells were activated by particles conjugated with Abs against human CD2, $\mathrm{CD} 3$, and CD28 for $48 \mathrm{~h}$ in the presence of the indicated concentrations of IQ1S. The results of 6 experiments are presented. Percentages of CD25 ${ }^{+} \mathrm{T}$ cells are presented. ${ }^{*} \mathrm{P}<0.05$, as compared to T-cell cultures in the absence of IQ-1S.

Todosenko et al., 2016).

First, we addressed direct effects of IQ-1S on membrane expression of an early $\mathrm{T}$ cell activation marker CD25 (IL-2 receptor $\alpha$ chain). We showed previously that T-cell activation resulted in significant increases in CD25 ${ }^{+}$T-cell numbers in all T-cell subsets tested (Shmarov et al., 2016; Todosenko et al., 2016; Meniailo et al., 2017; Malashchenko et al., 2018). Table 3 and Fig. 2 provide evidence that IQ-1S at $25 \mu \mathrm{M}$ significantly decreased activated $\mathrm{CD}^{2} 5^{+}$cell numbers in all T-cell subsets. In particular, $\mathrm{CD}^{+}{ }^{+} \mathrm{CD} 45 \mathrm{RA}^{-} \mathrm{CD} 197^{-}$and $\mathrm{CD}^{-} \mathrm{CD}^{-} 5 \mathrm{RA}^{-} \mathrm{CD}^{-} 7^{-}$effector memory $\mathrm{T}$ cells and $\mathrm{CD}^{-}{ }^{-} \mathrm{CD} 45 \mathrm{RA}^{-} \mathrm{CD}_{197}{ }^{+}$central memory $\mathrm{T}$ cells displayed increased sensitivity to IQ-1S-mediated suppressive activity at $5 \mu \mathrm{M}$ (Table 3 and Fig. 3). Of note, treatment with IQ-1S at $0.5 \mu \mathrm{M}$ had no significant effects on membrane CD25 expression (Table 3 ).

IFN- $\gamma$ and IL- 4 production is characteristic of Th1-versus Th2-type T-cell activity, respectively, while IL-10 is produced predominantly by regulatory T cells. T-cell activation dramatically increased IL-2, IFN- $\gamma$, IL-4, and IL-10 production in our in vitro experiments (Shmarov et al., 2016; Todosenko et al., 2016; Meniailo et al., 2017; Malashchenko et al., 2018). As can be seen in Table 4, treatment with IQ-1S at 5 and $25 \mu \mathrm{M}$ concentrations strongly suppressed T-cell production of all cytokines studied .

\section{Discussion}

In various target cells, JNKs stimulate transcriptional NF-kB activity resulting in pronounced anti-inflammatory, neuroprotective and cardioprotective effects, which appear to be largely immune-based and associated with the downregulation of NF-кB/AP-1 activation (Schepetkin et al., 2012, 2015; Atochin et al., 2016Shvedova et al., 2018Plotnikov et al., 2019)..

The anti-inflammatory effects of JNK inhibitors (mainly SP600125) were previously reported in several experimental models (Neacsu et al., 2015; Wang et al., 2017).Macrophages are endowed with effector, antigen-presenting and immunoregulatory properties, which underlie their versatile roles in innate and adaptive immunity, and macrophage functional activity has been shown to enhance dramatically upon activation. Our study is first report demonstrating effect of specific JNK inhibition on phenotype and cytokine production patterns of macrophage cells. In this study, macrophages were treated with JNK inhibitor
IQ-1S $(0.5-25 \mu \mathrm{M})$, which resulted in a significant reduction in $\mathrm{CD} 197^{+}$ cell numbers (but not $\mathrm{CD} 16^{+}, \mathrm{CD} 119^{+}$and $\mathrm{CD} 124^{+}$cells) in activated macrophage cultures. $\mathrm{CD} 197^{+}$(CCR7) chemokine receptor and its ligands (CCL19 and CCL21) are known to be instrumental in linking innate and adaptive immunity via several mechanisms, such as: (i) controlling T-cell-dendritic cell (DC) interactions, (ii) homing of naïve T cells, regulatory T cells, M1-type macrophages to secondary lymphoid organs, and (iii) promoting DC migration into afferent lymphatic vessels (Xuan et al., 2015). In agreement with these observations, inhibition of CCR7 and up-regulation of CCR5 expression have been shown previously to promote migration of immune cells in the periphery to the sites of inflammation (Barratt-Boyes et al., 2000; Geginat et al., 2001). It is tempting to speculate that accumulation of monocytes/macrophages in inflammatory sites (such as that mediated via JNK-dependent mechanisms) would nurture conditions for antigen uptake, processing and presentation, with subsequent macrophage-DC differentiation, thus effectively promoting inductive immunogenesis in the periphery. However, targeted NF- $\mathrm{KB}$ inhibition is known to drive DC functional polarization via a tolerogenic (as opposed to immunogenic) pathway (Yang et al., 2003; Prado et al., 2019). Under such circumstances, migration of tolerogenic DCs into lymphoid tissues should constrain T cell immunogenesis and subsequent development of $\mathrm{T}$ cell memory. Tolerogenic DC-driven immunosuppression could be at least partially mediated through stimulation of regulatory T-cell activity (Schepetkin et al., 2015).

CD119 and CD124 are receptors for IFN- $\gamma$ and IL-4, respectively. Th1-type cytokines (primarily IFN- $\gamma$ ) and LPS are known to promote macrophage polarization via classical pro-inflammatory (M1-type) pathway, which empowers macrophage with the ability for antigen presentation, protection against intracellular pathogens, as well as tumour destruction. On the other hand, Th2-type cytokines (primarily IL4) drive anti-inflammatory macrophage polarization via an alternative (M2-type) pathway, which reduces antigen presenting macrophage ability. However, M2-type macrophages are important in protection against extracellular pathogens, wound healing and tissue repair (Seledtsov and Seledtsova, 2012; Shapouri-Moghaddam et al., 2018). In this report, IQ-1S did not significantly affect the ratio of IFN- $\gamma$-sensitive/IL-4-sensivive macrophages. In addition, we observed that IQ-1S was equally efficient in suppressing pro-inflammatory (TNF, IL-1 $\beta$, IL6) and anti-inflammatory (IL-10) cytokine production in macrophage cultures, suggesting that IQ-1S-mediated anti-inflammatory effect was unlikely to be associated with macrophage polarization.

JNK signaling has been shown to regulate multiple biological processes in T cells related to T-cell activation, differentiation (Th1-type), cytokine production, apoptosis, and Treg functions (Rincón and Pedraza-Alva, 2003; Rincón and Davis, 2009). Therefore, JNKs represent excellent therapeutic targets for both direct targeting and/or co-targeting in the treatment of T-cell driven autoimmune disorders, such as rheumatoid arthritis (Bogoyevitch et al., 2010; Schepetkin et al., 2015) and psoriasis (Chen et al., 2013). Here we present experimental evidence that IQ-1S could directly suppress T-cell activation, as judged from the down-regulation of both CD25 membrane expression and cytokine production. We also showed that memory $\mathrm{T}$ cells were more sensitive to IQ-1S than naïve T cells, suggesting a possible therapeutic context for IQ-1S application for targeting pathogenic memory $\mathrm{T}$ cells, which are responsible for the development of both autoimmune and allergic diseases (Seledtsov and Seledtsova, 2019). In agreement with this concept, a pronounced therapeutic activity of IQ1S has been demonstrated previously in collagen-induced arthritis model and murine delayed-type hypersensitivity in vivo (Schepetkin et al., 2012, 2015). Our study shed more light on the mechanisms underlying IQ-1S-mediated effects on T cells in that this inhibitor suppressed production of IL-2, IFN-y, IL-4, and IL-10 by T cells. Our data suggests that IQ-1S-dependent immunomodulating activity targeted both Th1 and Th2-mediated immune responses, thus providing further support for potential clinical IQ-1S application for treating various 

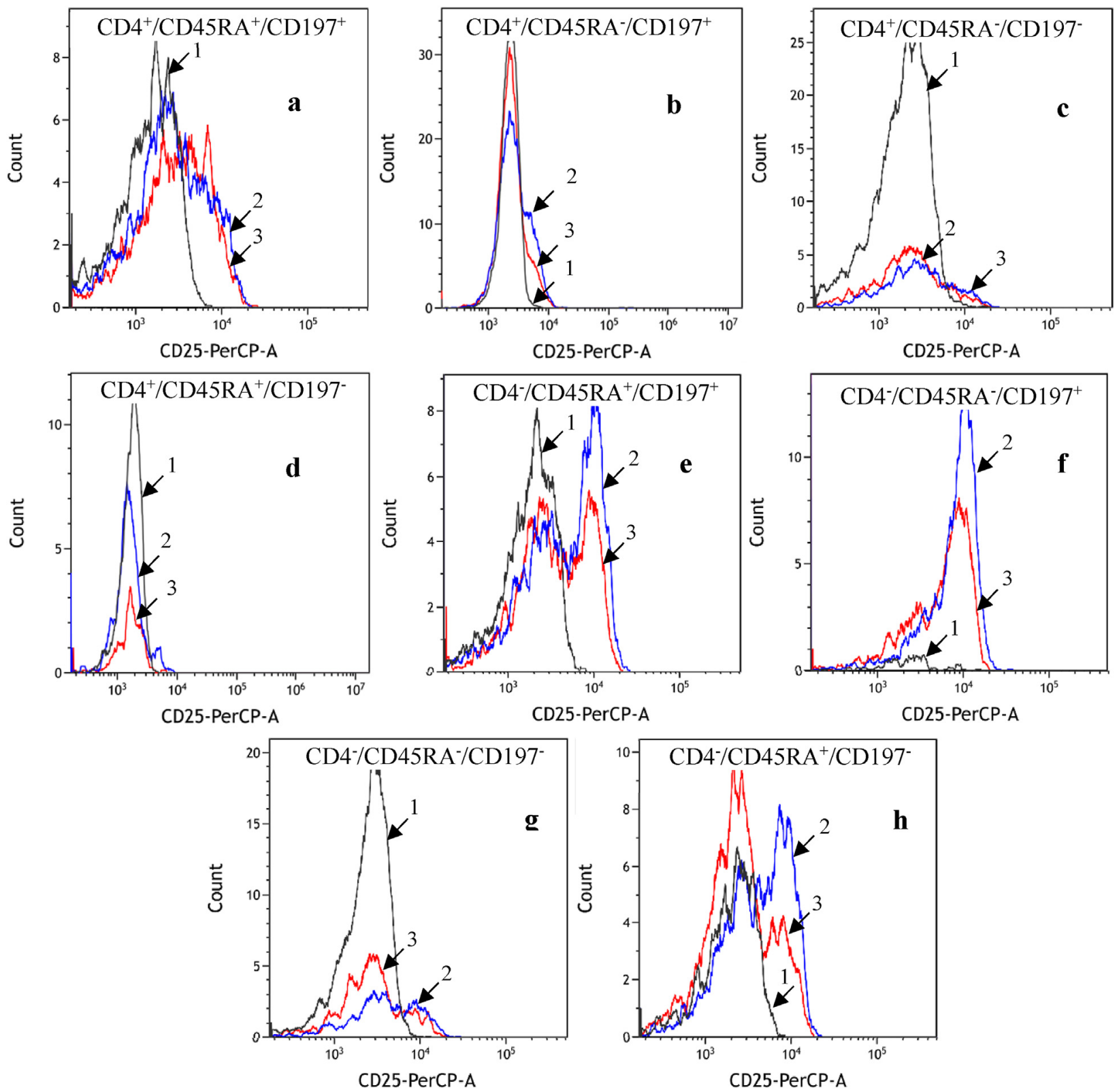

Fig. 2. The effect of IQ-1S ( $25 \mu \mathrm{M}, 48 \mathrm{~h}$ incubation) on relative numbers of $\mathrm{CD} 25^{+} \mathrm{T}$ cells in various T-cell subsets activated by particles conjugated with Abs against

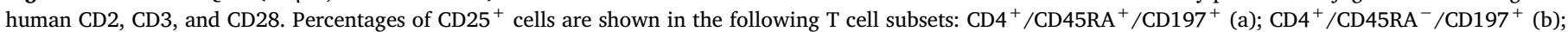

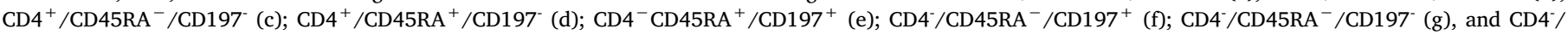
$\mathrm{CD}^{2} \mathrm{RA}^{+} / \mathrm{CD}^{-197^{-}}$(h). (1) Control T-cell cultures (without activator); (2) T cells activated in the absence of IQ-1S; (3) T cells activated in the presence $25 \mu \mathrm{M}$ of IQ$1 \mathrm{~S}$.

immune disorders driven both by pathogenic Th1 cells (such as rheumatoid arthritis and multiple sclerosis) and by pathogenic Th2 cells (asthma, atopic dermatitis and other allergic diseases). To our knowledge, this is first report demonstrating effect of specific JNK inhibitor on functionality of $\mathrm{T}$ cell subsets. It is important that the pathological antibody production observed in immunological disorders is typically highly T-cell-dependent (Seledtsov and Seledtsova, 2017, 2019). Therefore, inhibition of the functional activity of pathogenic $\mathrm{T}$ cells should inevitably lead to a decrease in the production of pathological antibodies.

Multiple studies clearly demonstrated that a small molecule inhibitor IQ-1S controls the biological activity of JNK in vitro. Nevertheless, there could be other unrelated mechanisms involved in its immunomodulating properties observed in this study. Indeed, some structurally similar compounds to IQ-1S were shown to exhibit JNK- independent properties. Thus, several $(11 H$-indeno[1,2- $\beta]$ quinoxalin11-ylidene)benzohydrazide derivatives with structural homology to IQ$1 \mathrm{~s}$ turned out to be $\alpha$-glucosidase inhibitors (Khan et al., 2014), i.e. the class of drugs also known to possess indirect anti-inflammatory, immunosuppressive and immunomodulatory activity (Willenborg et al., 1992; Van den Broek et al., 1996) mediated primarily via lowering the post prandial glucose levels in vivo.

\section{Conclusions}

A specific JNK inhibitor IQ-1S directly suppress activation and cytokine production in both human macrophages and T cells in vitro. IQ1S-mediated immunological effects observed here were not likely to be associated with M1/M2 macrophage and/or Th1/Th2 polariation. The evidence was obtained that IQ-1S targets more efficiently memory $\mathrm{T}$ 
a

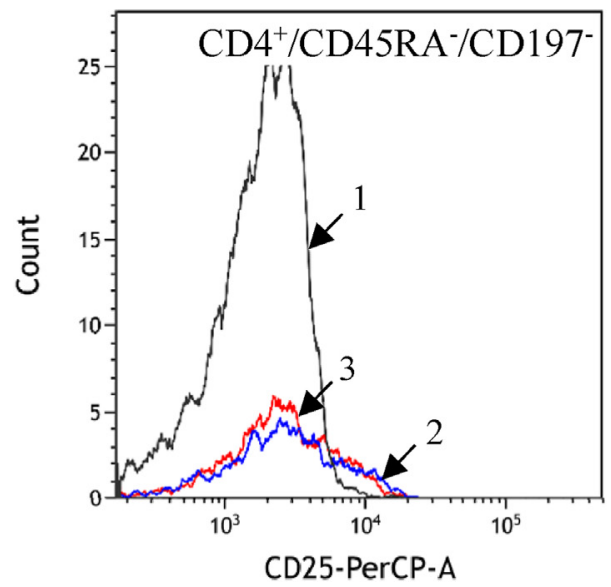

b

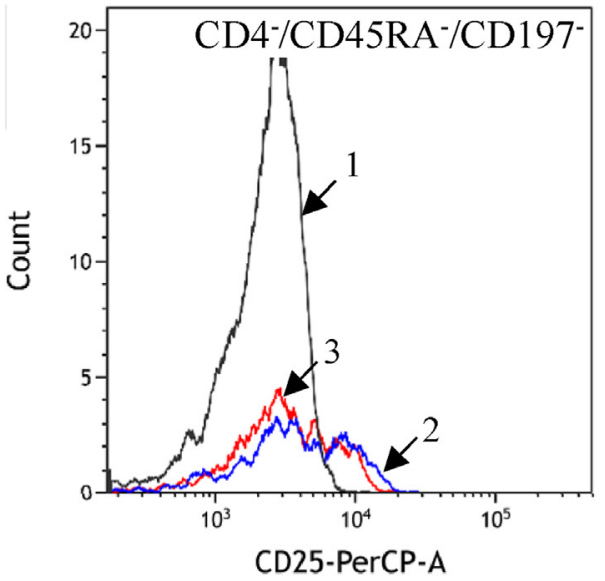

c

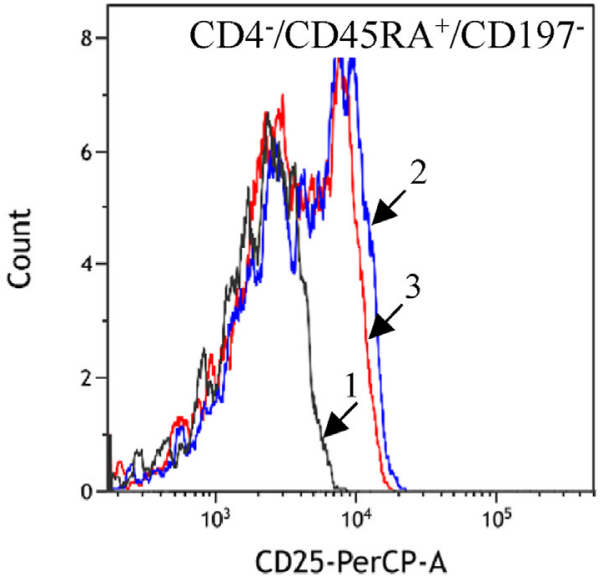

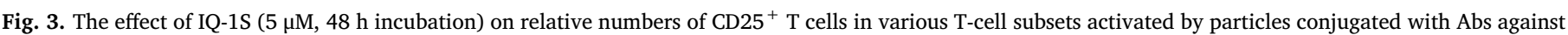

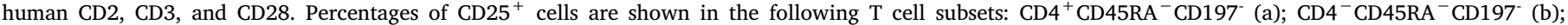

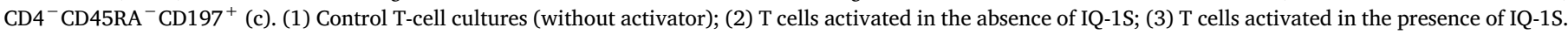

Table 4

The effects of IQ-1S on cytokine production by activated T cells.

\begin{tabular}{lllll}
\hline \multirow{2}{*}{ Cytokine } & \multicolumn{4}{l}{ IQ-1S concentrations $(\mu \mathrm{M})$} \\
\cline { 2 - 5 } & 0 & 0.5 & 5 & 25 \\
\hline IL-2 & 1066 & 1204 & $80^{*}$ & $<5^{*}$ \\
& $(284-522)$ & $(480-2144)$ & $(40-120)$ & \\
IFN- $\gamma$ & 1948 & 2831 & 387 & $<10^{*}$ \\
& $(974-6700)$ & $(1152-8050)$ & $(189-4754)$ & \\
IL-4 & 11 & 13 & 5 & $<5^{*}$ \\
& $(4-32)$ & $(8-27)$ & $(1-5)^{*}$ & 13 \\
IL-10 & 317 & 252 & 16 & 13 \\
& $(195-616)$ & $(128-513)$ & $(5-166)^{*}$ & $(6-20)^{*}$ \\
\hline
\end{tabular}

$\mathrm{T}$ cells were activated by particles conjugated with Abs against human $\mathrm{CD} 2$, $\mathrm{CD} 3$, and CD28 for $48 \mathrm{~h}$ in the presence of the indicated concentrations of IQ1S. The results of 5 experiments are presented. Cytokine concentrations in cell supernatants (pg/ml) are shown. ${ }^{*} \mathrm{P}<0.05$, as compared to $\mathrm{T}$ cell cultures in the absence of IQ-1S.

cells, as compared to naïve $\mathrm{T}$ cells. Taken together, our results provide further insight into mechanisms underlying immunosuppressive effects of specific JNK inhibition and substantiate further investigations into its immunotherapeutic anti-inflammatory application in experimental and clinical settings.

\section{CRediT authorship contribution statement}

Victor I. Seledtsov: Conceptualization, Methodology, Writing review \& editing. Vladimir V. Malashchenko: Writing - original draft, Investigation. Maksim E. Meniailo: Visualization, Investigation. Dmitriy N. Atochin: Supervision. Galina V. Seledtsova: Software, Validation. Igor A. Schepetkin: Project administration, Writing - review \& editing.

\section{Declaration of competing interest}

The authors declare that they have no conflict of interest.

\section{Acknowledgments}

We thank Dr. Shmarov V.A. for technical assistance in performing cell cytofluorometry.

\section{Appendix A. Supplementary data}

Supplementary data to this article can be found online at https:// doi.org/10.1016/j.ejphar.2020.173116.

\section{References}

Atochin, D.N., Schepetkin, I.A., Khlebnikov, A.I., Seledtsov, V.I., Swanson, H., Quinn, M.T., Huang, P.L., 2016. A novel dual NO-donating oxime and c-Jun N-terminal kinase inhibitor protects against cerebral ischemia-reperfusion injury in mice. Neurosci. Lett. 618, 45-49. https://doi.org/10.1016/j.neulet.2016.02.033.

Barratt-Boyes, S.M., Zimmer, M.I., Harshyne, L.A., Meyer, E.M., Watkins, S.C., Capuano, S., Murphey-Corb, M., Falo Jr., L.D., Donnenberg, A.D., 2000. Maturation and trafficking of monocyte-derived dendritic cells in monkeys: implications for dendritic cell-based vaccines. J. Immunol. 164, 2487-2495. https://doi.org/10.4049/ jimmunol.164.5.2487.

Bennett, B.L., Satoh, Y., Lewis, A.J., 2003. JNK: a new therapeutic target for diabetes. Curr. Opin. Pharmacol. 3, 420-425.

Bhagwat, S.S., 2009. Kinase inhibitors for the treatment of inflammatory and autoimmune disorders. Purinergic Signal. 5, 107-115. https://doi.org/10.1007/s11302008-9117-z.

Bogoyevitch, M.A., Ngoei, K.R., Zhao, T.T., Yeap, Y.Y., Ng, D.C., 2010. c-Jun N-terminal kinase (JNK) signaling: recent advances and challenges. Biochim. Biophys. Acta 1804, 463-475. https://doi.org/10.1016/j.bbapap.2009.11.002.

Chen, L., Wu, J., Ren, W., Yang, X., Shen, Z., 2013. c-Jun N-terminal kinase (JNK)phospho-c- Jun (ser63/73) pathway is essential for FOXP3 nuclear translocation in psoriasis. J. Dermatol. Sci. 69, 114-121. https://doi.org/10.1016/j.jdermsci.2012. 10.018 .

Fujioka, S., Niu, J., Schmidt, C., Sclabas, G.M., Peng, B., Uwagawa, T., Li, Z., Evans, D.B., Abbruzzese, J.L., Chiao, P.J., 2004. NF-kB and AP-1 connection: mechanism of NF-kBdependent regulation of AP-1 activity. Mol. Cell Biol. 24, 7806-7819. https://doi. org /10.1128/MCB. 24.17.7806-7819.2004.

Geginat, J., Sallusto, F., Lanzavecchia, A., 2001. Cytokine-driven proliferation and differentiation of human naive, central memory, and effector memory CD4(+) T cells. J. Exp. Med. 194, 1711-1719. https://doi.org/10.1084/jem.194.12.1711.

Gupta, S.C., Sundaram, C., Reuter, S., Aggarwal, B.B., 2010. Inhibiting NF-кB activation by small molecules as a therapeutic strategy. Biochim. Biophys. Acta 1799, 775-787. https://doi.org/10.1016/j.bbagrm.2010.05.004.

Jung, D.H., Park, H.J., Byun, H.E., Park, Y.M., Kim, T.W., Kim, B.O., Um, S.H., Pyo, S., 2010. Diosgenin inhibits macrophage-derived inflammatory mediators through downregulation of CK2, JNK, NF-KB and AP-1 activation. Int. Immunopharm. 10, 1047-1054. https://doi.org/10.1016/j.intimp.2010.06.004.

Khan, M.S., Munawar, M.A., Ashraf, M., Alam, U., Ata, A., Asiri, A.M., Kousar, S., Khan, M.A., 2014. Synthesis of novel indenoquinoxaline derivatives as potent $\alpha$-glucosidase inhibitors. Bioorg. Med. Chem. 22, 1195-1200. https://doi.org/10.1016/j.bmc.2013. 12.024

Melashchenko, O.V., Meniailo, M.E., Malashchenko, V.V., Gazatova, N.D., Goncharov, A.G., Seledtsova, G.V., Seledtsov, V.I., 2018. Erythropoietin directly affects human macrophage functionality. Curr. Pharmaceut. Biotechnol. 19, 902-909. https://doi. org $/ 10.2174 / 1389201019666181031164520$

Malashchenko, V.V., Meniailo, M.E., Shmarov, V.A., Gazatova, N.D., Melashchenko, O.B., Goncharov, A.G., Seledtsova, G.V., Seledtsov, V.I., 2018. Direct anti-inflammatory effects of granulocyte colony-stimulating factor (G-CSF) on activation and functional properties of human $\mathrm{T}$ cell subpopulations in vitro. Cell. Immunol. 325, 23-32. https://doi.org/10.1016/j.cellimm.2018.01.007. 
Meniailo, M.E., Malashchenko, V.V., Shmarov, V.A., Gazatova, N.D., Melashchenko, O.B., Goncharov, A.G., Seledtsova, G.V., Seledtsov, V.I., 2017. Direct effects of interleukin8 on growth and functional activity of T lymphocytes. Int. Immunopharm. 50 , 178-185. https://doi.org/10.1016/j.intimp.2017.06.023. 2017.

Meniailo, M.E., Malashchenko, V.V., Shmarov, V.A., Gazatova, N.D., Melashchenko, O.B., Goncharov, A.G., Seledtsova, G.V., Seledtsov, V.I., 2018. Interleukin-8 favors proinflammatory activity of human monocytes/macrophages. Int. Immunopharm. 56, 217-221. https://doi.org/10.1016/j.intimp.2018.01.036.

Neacsu, P., Mazare, A., Schmuki, P., Cimpean, A., 2015. Attenuation of the macrophage inflammatory activity by $\mathrm{TiO}_{2}$ nanotubes via inhibition of MAPK and NF-кB pathways. Int. J. Nanomed. 10, 6455-6467. https://doi.org/10.2147/IJN.S92019.

Pearson, B.D., 1962. Indenoquinolines. III. Derivatives of $11 H$-indeno-[1,2-b]quinoxaline and related indenoquinolines. J. Org. Chem. 27, 1674-1678.

Peng, S.L., 2008. Transcription factors in autoimmune diseases. Front. Biosci. 13, 4218-4240. https://doi.org/10.2741/3001.

Plotnikov, M.B., Chernysheva, G.A., Aliev, O.I., Smol'iakova, V.I., Fomina, T.I., Osipenko, A.N., Rydchenko, V.S., Anfinogenova, Y.J., Khlebnikov, A.I., Schepetkin, I.A., Atochin, D.N., 2019. Protective effects of a new c-Jun N-terminal kinase inhibitor in the model of global cerebral ischemia in rats. Molecules 24. https://doi.org/10.3390/ molecules24091722.

Prado, C., Ugalde, V., González, H., Figueroa, A., López, E., Lladser, A., Pacheco, R., 2019. STAT3 activation in combination with NF- $\mathrm{B}$ inhibition induces tolerogenic dendritic cells with high therapeutic potential to attenuate collagen-induced arthritis. J. Immunol Res. 2019, 1982570. https://doi.org/10.1155/2019/1982570.

Rincón, M., Davis, R.J., 2009. Regulation of the immune response by stress-activated protein kinases. Immunol. Rev. 228, 212-224. https://doi.org/10.1111/j.1600-065X. 2008.00744.x.

Rincón, M., Pedraza-Alva, G., 2003. JNK and p38 MAP kinases in CD4 + and CD8 + T cells. Immunol. Rev. 192, 131-142. https://doi.org/10.1034/j.1600-065x.2003. 00019.x.

Schepetkin, I.A., Kirpotina, L.N., Hammaker, D., Kochetkova, I., Khlebnikov, A.I., Lyakhov, S.A., Firestein, G.S., Quinn, M.T., 2015. Anti-Inflammatory effects and joint protection in collagen-induced arthritis after treatment with IQ-1S, a selective c-Jun N-terminal kinase inhibitor. J. Pharmacol. Exp. Therapeut. 353, 505-516. https:// doi.org/10.1124/jpet.114.220251.

Schepetkin, I.A., Kirpotina, L.N., Khlebnikov, A.I., Hanks, T.S., Kochetkova, I., Pascual, D.W., Jutila, M.A., Quinn, M.T., 2012. Identification and characterization of a novel class of c-Jun N-terminal kinase inhibitors. Mol. Pharmacol. 81, 832-845. https:// doi.org/10.1124/mol.111.077446.

Seledtsov, V.I., Seledtsova, G.V., 2012. A balance between tissue-destructive and tissueprotective immunities: a role of toll-like receptors in regulation of adaptive immunity. Immunobiology 217, 430-435. https://doi.org/10.1016/j.imbio.2011.10. 011.

Seledtsov, V.I., Seledtsova, G.V., 2017. A possible role for idiotype/anti-idiotype B-T cell interactions in maintaining immune memory. Front. Immunol. 8, 409. https://doi. org $/ 10.3389 /$ fimmu.

Seledtsov, V.I., Seledtsova, G.V., 2019. Total threshold cytotoxicity of therapeutic antibodies for selective destruction of pathogenic memory T cells: implications for immunotherapy of autoimmune and allergenic disorders. Expet Rev. Clin. Immunol. 15, 701-706. https://doi.org/10.1080/1744666X.2019.1617698.

Shapouri-Moghaddam, A., Mohammadian, S., Vazini, H., Taghadosi, M., Esmaeili, S.A., Mardani, F., Seifi, B., Mohammadi, A., Afshari, J.T., Sahebkar, A., 2018. Macrophage plasticity, polarization, and function in health and disease. J. Cell. Physiol. 233, 6425-6440. https://doi.org/10.1002/jcp.26429.

Shmarov, V.A., Malashchenko, V.V., Meniailo, M.E., Gazatova, N.D., Todosenko, N.M., Melashchenko, O.B., Goncharov, A.G., Seledtsov, V.I., 2016. Direct effects of interleukin-7 on the function of human T cells in vitro. Eur. Cytokine Netw. 27, 102-107. https://doi.org/10.1684/ecn.2016.0385.

Shvedova, M., Anfinogenova, Y., Atochina-Vasserman, E.N., Schepetkin, I.A., Atochin, D.N., 2018. c-Jun N-Terminal Kinases (JNKs) in myocardial and cerebral ischemia/ reperfusion injury. Front. Pharmacol. 9, 715. https://doi.org/10.3389/fphar.2018. 00715.

Todosenko, N.M., Shmarov, V.A., Malashchenko, V.V., Meniailo, M.E., Melashchenko, O.B., Gazatova, N.D., Goncharov, A.G., Seledtsov, V.I., 2016. Erythropoietin exerts direct immunomodulatory effects on the cytokine production by activated human Tlymphocytes. Int. Immunopharm. 36, 277-281. https://doi.org/10.1016/j.intimp. 2016.05.006.

Van den Broek, L.A., Kat-Van Den Nieuwenhof, M.W., Butters, T.D., Van Boeckel, C.A., 1996. Synthesis of alpha-glucosidase I inhibitors showing antiviral (HIV-1) and immunosuppressive activity. J. Pharm. Pharmacol. 172-178. https://doi.org/10.1111/ j.2042-7158.1996.tb07117.x.

Wagner, G., Laufer, S., 2006. Small molecular anti-cytokine agents. Med. Res. Rev. 26, 1-62. https://doi.org/10.1002/med.20042.

Wang, H.L., Tsao, S.M., Yeh, C.B., Chou, Y.E., Yang, S.F., 2017. Circulating level of high mobility group box-1 predicts the severity of community-acquired pneumonia: regulation of inflammatory responses via the c-Jun N-terminal signaling pathway in macrophages. Mol. Med. Rep. 16, 2361-2366. https://doi.org/10.3892/mmr.2017. 6892.

Willenborg, D.O., Parish, C.R., Cowden, W.B., 1992. Inhibition of adjuvant arthritis in the rat by phosphosugars and the alpha-glucosidase inhibitor castanospermine. Immunol. Cell Biol. 70 (Pt 6), 369-377. https://doi.org/10.1038/icb.1992.49.

Xuan, W., Qu, Q., Zheng, B., Xiong, S., Fan, G.H., 2015. The chemotaxis of M1 and M2 macrophages is regulated by different chemokines. J. Leukoc. Biol. 97, 61-69. https://doi.org/10.1189/jlb.1A0314-170R.

Yang, J., Bernier, S.M., Ichim, T.E., Li, M., Xia, X., Zhou, D., Huang, X., Strejan, G.H., White, D.J., Zhong, R., Min, W.P., 2003. LF15-0195 generates tolerogenic dendritic cells by suppression of NF-KB signaling through inhibition of IKK activity. J. Leukoc. Biol. 74, 438-447. https://doi.org/10.1189/jlb.1102582. 